\title{
REFLETINDO SOBRE A PROPOSTA DA PEDAGOGIA DA GRATUIDADE
}

\section{REFLECTING ON THE PROPOSAL OF THE PEDAGOGY OF GRATUITY}

\author{
Everton Nery Carneiro ${ }^{1}$ \\ Jefferson Zeferino ${ }^{2}$
}

\begin{abstract}
Resumo
Com o desafio de se pensar uma cultura de humanização, este texto, por meio de uma análise bibliográfica, tem por objetivo pensar na construção de uma pedagogia da gratuidade tendo por base a teologia barthiana e a pedagogia freireana. Essa pedagogia da gratuidade é proposta como modo de traduzir a vontade de produção de uma cultura humanista de cuidado e amor ao próximo em sua diversidade. Ela é também uma pedagogia existencial que apreende a vida e as alteridades como graça. Enfatizam-se a criatividade, a reconciliação e a esperança como desdobramentos da gratuidade. A co-humanidade, por sua vez, se reflete de modo prático no cuidar como o centro da dimensão ética da gratuidade. Nesse sentido consideramos a existência de uma disposição baricêntrica de ser com o outro e, no reconhecimento e acolhida do próprio inacabamento, ser mais.
\end{abstract}

Palavras-chave: Teologia Pública; Pedagogia da gratuidade; Ser mais; Co-humanidade; Cuidar.

\begin{abstract}
This work, based on a bibliographical analysis, faces the challenge to think a humanization culture aiming at constructing a pedagogy of gratitude drawing from Karl Barth's theology and Paulo Freire's pedagogy. This pedagogy of gratitude translates the will to produce a humanist culture of care and love of the neighbors in their diversity. So, it is also an existential pedagogy that comprehends life and the alterities as grace. There is a focus on creativity, reconciliation and hope as outcomes of gratitude. In this sense, fellow-humanity reflects in a practice way the act of caring as the center of gratitude ethical dimension. Therefore, we consider the existence of a gravity center disposition in which by being with the other, acknowledging and welcoming one's own incompleteness, it is possible to be more.
\end{abstract}

Keywords: Public Theology; Pedagogy of gratitude; Be more; Fellow-humanity; Act of caring.

\footnotetext{
${ }_{1}^{1}$ Doutor em Teologia pela Escola Superior de Teologia. Docente no Programa de Pós-Graduação em Intervenção Educativa e Social Universidade do Estado da Bahia.

Contato: ecarneiro@uneb.br

ORCID: https://orcid.org/0000-0002-4240-1246

2 Doutor em Teologia pela Pontifícia Universidade Católica do Paraná. Professor no Programa de PósGraduação em Teologia da Pontifícia Universidade Católica do Paraná e na Maestría en Teología da Facultad Evangélica de Estudios Teológicos.

Contato: jefferson.zeferino@hotmail.com
}

ORCID: https://orcid.org/0000-0002-5376-4587 


\section{Introdução}

A educação transcende o âmbito formal de ensino abrangendo a sociedade em seus mais variados níveis. Nesse sentido, se pode pensar num espírito educacional conectado à um projeto de humanidade. A construção de uma cultura humanista, portanto, pode haurir da força de sentido das mais variadas produções culturais em sua constante tarefa de tradução da alma humana em arte, filosofia, religião. Eis o escopo daquilo que David Tracy (2006) apresenta como um método de teologia pública ${ }^{3}$, a saber, uma correlação crítica entre a hermenêutica da condição humana na situação contemporânea e a hermenêutica dos clássicos da razão, da arte e da religião. Há uma ênfase na criticidade para que aquilo que quer ser pensado não seja recebido sem a devida problematização e análise, ao mesmo tempo, apresenta-se uma metodologia abrangente que entende que para investigar a complexidade da experiência humana hoje é necessária uma pluralidade de saberes e sabores - para incluir na discussão a urgência de uma hermenêutica da carne como proposta por Richard Kearney (2015).

Assim, diante da fragmentação cada vez mais acelerada das relações humanas, não por último evidenciada pela pandemia da Covid-19, propõe-se uma abordagem intercultural e interdisciplinar no âmbito das humanidades, incluídas aí a teologia e a pedagogia.

Se, por um lado, o sofrimento pode ser considerado a experiência humana mais comum (cf. RICOEUR, 2002; ZEFERINO, FERNANDES, 2020), por outro, a gratuidade pode, inclusive, anteceder a experiência. Recebe-se algo antes mesmo de ser. A vida, interpretada como dom, é graça compartilhada e experimentada por todos seres viventes. Assim sendo, do mesmo modo que pensar a vida humana alheia ao

\footnotetext{
${ }^{3}$ Para uma introdução aos estudos sobre teologia pública no Brasil ver as recentes publicações $A$ política como assunto dos estudos em teologia pública: aportes na relação entre religião e espaço público à luz da tipologia de teologias políticas de Boaventura de Sousa Santos (ZEFERINO, 2019), em que o autor apresenta o exercício da teologia pública em seus momentos crítico-analítico e críticopropositivo; e A teologia pública no Brasil: análise de um mapeamento (ZEFERINO, 2020), em que se demonstra o quadro temático das pesquisas sobre teologia pública nas duas últimas décadas no contexto brasileiro.
} 
sofrimento é alienação, tentar compreender a existência negligenciando a graça também o é.

Com o desafio de se pensar uma cultura de humanização diante de cenários alarmantes em que impera o risco excarnacionista (cf. KEARNEY, 2014) de desumanização do outro, emerge a necessidade de se pensar o humano em sua profundidade de sentidos. Assim, ao se considerar, em companhia de Clodovis Boff (2014), que o sentido só faz sentido quando é sentido, reconhece-se a emergência de uma hermenêutica não mais racional do que sensível. Assim, naquilo que se pode considerar um exercício fenomenológico, observa-se que da experiência humana se manifesta o que nos une a todos em nossa humanidade. Nas produções culturais, por sua vez, nota-se uma força de sentido que promove o florescimento humano em relações de afirmação do outro, de cuidado, práxis de amor e gratuidade.

Diante disso, uma pedagogia da gratuidade é proposta como modo de traduzir a vontade de produção de uma cultura humanista de cuidado e amor ao próximo em sua diversidade, recebendo-o como um dom. Nesse sentido, uma pedagogia da gratuidade é também uma pedagogia existencial que apreende a vida e as alteridades como graça.

O estofo teórico dessa abordagem se nutre do pensamento teológico barthiano e da abordagem educativa freireana. Do primeiro, apresenta-se a graça como base de sua argumentação dogmática a ser traduzida no esquema ternário criatividadereconciliação-esperança. Do segundo, além do alargamento teórico, colhem-se elementos de tradução pública daquelas intuições teológicas barthianas e de seu aprofundamento.

\section{Por uma pedagogia da gratuidade}

A graça é a fonte mais elementar do pensamento barthiano. Mas como entender essa graça no contexto de uma teologia pública? Isto é, diante da necessidade de tradução do pensamento teológico para uma linguagem adequada ao âmbito acadêmico. Com efeito, a questão da graça é aqui pensada em sua dimensão relacional, por isso, opta-se por investigar a força de sentido daquilo que se pode 
chamar de gratidão e gratuidade e como essas categorias podem ajudar a pensar a condição humana na situação contemporânea.

A seu modo cristocêntrico, Barth (1978) estabelece que não há formulação teológica sem base antropológica. Acresce-se a isso, a partir de David Tracy (2006), que são as grandes questões fundamentais do ser humano que movem o pensamento teológico. Desse modo, uma teologia pública da graça buscará redescobrir os testemunhos de gratidão e gratuidade presentes nas tradições teológicas e doá-las ao pensamento público em relação com outras produções culturais. Evidencie-se, portanto, que a presente abordagem se movimenta no contexto metodológico tracyano e opera uma tradução pública do pensamento teológico barthiano como um clássico teológico a ser correlacionado com o arcabouço teórico freireano. Um clássico, para Tracy (2006), é tudo aquilo que comunica ao humano algo de sua própria humanidade, podendo ser uma pessoa, um evento, alguma literatura, outras obras de arte etc. De certo modo, se quer propor que o clássico fundamental do pensamento barthiano é a graça, esta, por sua vez, se desdobra numa lógica trinitária em criação, reconciliação e redenção. O que se depreende da obra clássica de Barth, sua Dogmática Eclesial (Kirchliche Dogmatik = KD).

Barth intitula os volumes da KD como doutrinas (Lehre). Os cinco volumes, sendo que o último nunca chegou a ser escrito e o quarto restou não finalizado, são: A Doutrina da Palavra de Deus (Die Lehre vom Wort Gottes, KD I); A Doutrina de Deus (Die Lehre von Gott, KD II); A Doutrina da Criação (Die Lehre von der Schöpfung, KD III); A Doutrina da Reconciliação (Die Lehre von der Versöhnung, KD IV); e A Doutrina da Redenção (Die Lehre von der Erlösung, KD V). O termo alemão Lehre, por sua vez, também pode ser entendido como ensinamento, algo que pode ser pensando numa condição de horizontalidade e não de verticalidade como transparece a ideia de doutrina. Este ensinamento, ou pedagogia, portanto, parece estar mais próximo da própria tradição bíblica, como na ideia de Torá (instrução), no discipulado e na mistagogia como educação para a espiritualidade, e mesmo na postura de Jesus nos relatos evangélicos como aquele que ensina ao caminhar junto com as pessoas, conhecendo seus sofrimentos e se solidarizando numa práxis de amor (cf. JEANROND, 2010). Percebe-se na tradição cristã, portanto, uma dinâmica pedagógica que pensa a vida e instrui a ética. Assim, com base em critérios 
públicos de argumentação (TRACY, 2006) se pensa sua opus magna como uma pedagogia ética. Há, portanto, uma doação quenótica (de esvaziamento de si em favor do outro - kenosis) da linguagem teológica para dentro de um espectro cultural mais amplo. Nesse sentido, o diálogo entre Pedagogia e Teologia se efetiva por meio da busca de um solo conceitual comum.

Para além da base dogmático-cristocêntrica barthiana, pensam-se implicações de uma ética teológica abastecida por uma pedagogia da graça, uma Lehre von der Gnade (ensinamento sobre a graça) não enquanto doutrina, mas pedagogia. A partir de Barth, concebe-se a graça enquanto elemento fundante da ética que, por sua vez, é composta pela pericorética ${ }^{4}$ relação entre criatividade quenótica, perdão reconciliador e esperança ativa. Os grandes temas dos projetados três últimos volumes de sua KD, portanto, são aqui pensados em sua profundidade éticoantropológica. Já na KD III, o autor se ocupa da relação ternária destes termos. Com efeito, criação, reconciliação e redenção obedecem a lógica da economia trinitária em que Deus cria (Pai), reconcilia (Filho) e redime (Espírito Santo). A comunhão trinitária, portanto, é traduzida para dentro das relações intersubjetivas. A criação é percebida como força criativa, fundamental nas relações e no desenvolvimento do espírito humano e no reconhecimento de sua dignidade; a reconciliação é compreendida na potência restaurativa do perdão, sem deixar de considerar a ambiguidade da existência; a redenção é pensada em seu dinamismo escatológico ${ }^{5}$ de uma esperança ativa.

Dessa forma, a história da graça, vivida nas relações humanas, acontece num contínuo movimento de interlocuções, interpelações e interpenetrações das situações da vida que pedem por criatividade, reconciliação e redenção. Assim, a singularidade e a multiplicidade contidas nessa lógica de comunhão, são estabelecidas como elementos que permitem enxergar uma relação pericorética entre criatividade, perdão

\footnotetext{
4 Termo aportuguesado a partir da noção grega de perichoresis, utilizada na patrística para designar a relação entre as pessoas da Trindade. Uma tradução possível é interpenetração. (cf. BOFF, a trindade como a melhor comunidade).

${ }^{5}$ A escatologia é, na tradição cristã, o estudo das últimas coisas. Jon Sobrino (1990), por sua vez, a interpreta como aquilo que é último no pensamento cristão enfatizando o tema do Reino de Deus; Jürgen Moltmann (2005) coloca a ênfase da escatologia no tema da esperança; Vítor Westhelle (2012), em sua escatologia espacial, segue a ênfase na questão da esperança, pensando-a concretamente como na luta pela terra dos trabalhadores rurais.
} 
e esperança enquanto momentos de uma e mesma graça. (cf. BARTH, 1978; 1983; ZEFERINO, 2018).

Não por último, se faz necessário ver que são as convicções teológicas de Barth, que o levam a se posicionar veementemente contra outros movimentos teológicos que se transformaram em legitimadores de violências. Assim, a constante crítica e autocrítica do contexto social, histórico e teológico compõe o processo de elaboração de uma fala teológica que se quer pertinente nas questões da atualidade. As experiências das teologias que sustentaram a política bélica alemã na Primeira Grande Guerra, e a teologia dos Deutsche Christen em apoio ao nazismo, demonstram a contínua urgência de criticidade e auto-criticidade teórica. Do mesmo modo, as teologias hodiernas de apoio a posturas violentas e exclusivistas carecem de uma aproximação crítica, para que sejam também investigadas em suas alegações de sentido e verdade e desnudadas em suas inconsistências teóricas, uma vez que se pretendem representantes totalizantes da mensagem cristã. Apoia essa criticidade, a percepção de que cada discurso possui um certo pano de fundo político-ideológico que determina sua configuração. Nesse contexto, o olhar a partir de baixo ajuda um pensamento humanista a se colocar ao lado dos que sofrem, das vítimas, das pessoas excluídas e marginalizadas, informando que uma pedagogia da graça é também profética, conforme explicitaremos no diálogo com Freire. (cf. ZEFERINO, 2018).

Para se pensar adiante a presente proposta de uma pedagogia da gratuidade, parece-nos interessante trazer um autor cuja relevância para a Educação no Brasil e no mundo é inegável. Ademais, sua familiaridade com a teologia permite uma passagem da Teologia para a Educação de modo consistente. Paulo Freire (19211997), educador brasileiro engajado no pensamento de libertação, tem muito o que contribuir para o projeto ora proposto, basta citar alguns de seus principais trabalhos: Pedagogia da autonomia (1996), Educação como prática da liberdade (2000), Pedagogia da esperança (2007), Pedagogia da tolerância (2014), além de sua célebre Pedagogia do oprimido (1997). Começamos, porém, por sua reflexão sobre O papel educativo das Igrejas na América Latina, texto originário de 1971 e alocado em sua 
obra Ação cultural para a liberdade e outros escritos ${ }^{6}$. Nela, o autor apresenta elementos de base para o presente diálogo entre Pedagogia e Teologia.

Freire se dispõe a investigar a relação entre igrejas e educação historicamente, o que significa dizer a partir de seus contextos concretos. "No momento, porém, em que levamos a sério tais afirmações, já não podemos aceitar a neutralidade das igrejas em face da história, assim como a neutralidade da educação" (FREIRE, 2011). Outro pressuposto de sua fala é uma recusa da noção de que

[...] a consciência possa ser modificada fora da práxis. É preciso, contudo, salientarmos que a práxis através da qual a consciência se transforma, não é pura ação, mas ação e reflexão. [...] a unidade entre prática e teoria, em que ambas vão se constituindo, fazendo-se e refazendo-se num movimento permanente no qual vamos da prática à teoria e desta a uma nova prática. [...] [isto] significa, em outras palavras, que a reflexão só é verdadeira quando nos remete, como salienta Sartre, ao concreto sobre o qual a exercemos (FREIRE, 2011).

Aspecto bastante correlato a noção barthiana de que o pensamento só faz sentido quando parte da concreticidade da existência. Além disso, e enquanto resumo de sua articulação, postula que "[...] a teoria da qual viemos é a teoria da práxis" (BARTH, 2016, p. 421) ${ }^{7}$.

A educação, nesse contexto, precisa ser considerada uma educação para a libertação, sendo compreendia "[...] como prática social, a contribuir para a libertação das classes dominadas. Por isso mesmo, é uma educação política, tão política quanto a que, servindo às classes dominantes, se proclama, contudo, neutra" (FREIRE, 2011). Assim como, para Freire, a sociedade é dividida em distintas classes, também as igrejas refletem estas constituições, não sendo possível "[...] falar objetivamente de um papel unificado das Igrejas latino-americanas em face da educação. Há papéis distintos, em função da linha política, clara ou oculta ou disfarçada, que diferentes Igrejas vêm assumindo historicamente na América Latina" (FREIRE, 2011). Diante disso, o autor identifica três principais modos de ser igreja: o tradicionalista, o modernizante e o libertador.

\footnotetext{
${ }^{6}$ Texto organizado pelo autor e publicado inicialmente em 1975. Aqui utiliza-se a edição publicada em 2011, na sua versão ePub, em virtude disso, não há a indicação da paginação.

${ }^{7} \mathrm{O}$ aspecto da contextualidade do pensamento barthiano e sinalizada também por Taylor $(2015$, p. $323-$ 330) em New directions in Barthian ethics.
} 
O viés tradicionalista vê a mundanidade como sujeira, algo a ser purificado, é fatalista diante da situação das classes oprimidas, tende a fechar-se, isolar-se do mundo. "Desta forma, querem chegar à transcendência sem passar pela mundanidade; querem a meta história, sem experimentar-se na história; querem salvação sem libertação" (FREIRE, 2011). Em virtude disso, "sua concepção da educação, que se concretiza em uma prática correspondente, não pode deixar de ser quietista, alienada e alienante" (FREIRE, 2011). Esse campo é o da concepção bancária, sendo aquela que o educador assume um papel de dono da verdade e esta é emitida por ele, para o educando, que a recebe, tal qual um depósito, sendo isto feito de maneira passiva. O que ocorre é a memorização de uma fala, sem a compreensão de seu significado, ou seja, a sonorização de uma voz, de um discurso que pode fazer com que a palavra perca a sua força transgressora. Entendemos que o lastro da "concepção bancária" objetiva a manutenção do oprimido, ou seja, do educando, sem alteração na sua posição, sem transformação, assim, continuando de base para o opressor. O pensar filosófico, ou qualquer que seja o componente curricular, que ambicione a transgressão, ou a construção de um pensar libertário não é estimulado ou colocado em pauta, mas sim, abandonado.

A opção modernizante, por sua vez, é uma espécie de continuidade da tradicionalista. "Enquanto as Igrejas tradicionalistas alienam as classes sociais dominadas, revelando-Ihe o mundo como seu antagônico, a lgreja modernizante as aliena, em forma diferente, ao apoiar os reformismos que preservam o status quo" (FREIRE, 2011). Em relação a educação, "[...] ainda quando fale em educação para a libertação, tal educação esteja condicionada por sua visão da libertação como um quefazer individual que deve dar-se, sobretudo, no câmbio das consciências e não através da práxis social e histórica dos seres humanos" (FREIRE, 2011). Em virtude disso, enfatiza "[...] os métodos, tomados como instrumentos neutros" (FREIRE, 2011). Disso resulta que "a educação libertadora se reduz, [...] para a Igreja modernizante, a libertar educandos do quadro-negro, das aulas mais estáticas, dos conteúdos mais 'livrescos', oferecendo-Ihes projetores e outras ajudas audiovisuais, aulas mais dinâmicas e ensino técnico profissional" (FREIRE, 2011). Nesta concepção reina o tecnicismo e as práticas de treinamento. O treinar pode vir de um aprimorar, que passa pela dimensão da compreensão. Treinamento sem compreensão 
é tão somente repetição. Não há um perguntar por que fazer? Para que fazer? E para quem fazer? O que existe é o fazer. Assim, este é um fazer descontextualizado e descompromissado com a educação, pois se reverbera a absolutização da ignorância, que está fundada na ideologia opressiva, típica da sociedade que tem como lastro o capital e não o social, ou a economia e não a vida.

A igreja profética, opção apoiada por Freire, recupera a força libertadora da tradição profética judaico-cristã. "Finalmente, tão velha quanto o cristianismo mesmo, sem ser tradicional, tão nova quanto ele, sem ser modernizante, vem afirmando-se, cada vez mais, na América Latina, ainda que não como um todo coerente, uma outra linha de Igreja - a profética" (FREIRE, 2011). Este modelo recebe resistências, porém, "[...] a linha profética, utópica e esperançosa, recusando os paliativos assistencialistas, os reformismos amaciadores, se compromete com as classes sociais dominadas para a transformação radical da sociedade" (FREIRE, 2011). Assim, atua de forma concreta na sociedade por meio da dinâmica de anúncio e denúncia, pois "[...] ser profético, utópico e esperançoso [...] é denunciar e anunciar através da práxis real. Daí o conhecimento científico da realidade como condição necessária à eficiência profética" (FREIRE, 2011). Entretanto, esta atuação não pode acontecer "[...] sem as classes sociais dominadas, isto é, não podemos prescrever-lhes nossa denúncia e nosso anúncio" (FREIRE, 2011). Neste contexto, o fazer teológico "[...] cede lugar à teologia da libertação, profética, utópica, esperançosa, não importa que ainda não tão sistematizada" (FREIRE, 2011). O assunto da teologia, neste cenário, portanto, tem de ser aquele "[...] que emerge das condições objetivas das sociedades dependentes, exploradas, invadidas" (FREIRE, 2011). Isto é, que surge "[...] da necessidade da superação real das contradições que explicam tal dependência" (FREIRE, 2011). Assim, fala profética é fala contextual. "O testemunho profético, por ser histórico, é que se traduz de forma distinta, em tempos e espaço distintos" (FREIRE, 2011). Isto não quer dizer que não se possa fazer teologia profética fora da América Latina. Pelo contrário, "os europeus, de sociedades tecnologizadas, e os norte-americanos não têm necessidade de vir à América Latina para tornar-se proféticos" (FREIRE, 2011). Esta teologia requer que se atente profundamente as dinâmicas próprias da sociedade em que se vive, assim, "basta buscar a periferia de suas grandes cidades, sem 'inocência' ou 'esperteza', e aí encontrarão suficiente estímulo para repensar- 
se" (FREIRE, 2011). A educação neste contexto é educação transformadora, entendida "como práxis política a serviço da permanente libertação dos seres humanos, que não se dá, repitamos, nas suas consciências apenas, mas na radical modificação das estruturas em cujo processo se transformam as consciências" (FREIRE, 2011). Assim, educação profética é aquela que encarna de forma radical o contexto social, histórico e político em que se vive, desvelando as estruturas violentas de opressão, para que, a partir daí, com aqueles e aquelas que são furtados de suas cidadanias, se construa um movimento crítico e autocrítico de libertação responsável e cidadã. Precisamos deixar nítida a palavra de Paulo Freire em Cartas de Cristina: "Minha convivência com Marx jamais me sugeriu, sequer, meu afastamento de Cristo" (FREIRE, 2003, p.122).

Em uma palestra proferida no contexto de um evento voltado a relação entre Reforma - Educação - Transformação ${ }^{8}$, Rudolf von Sinner, importante pesquisador no âmbito dos estudos em teologia pública, pensa o aspecto da educação em especial relação com a tradição latino-americana, passando por Jon Sobrino, Hugo Assmann, bem como comentando o texto de Freire aqui analisado. De Sobrino, destaca o intellectus amoris como centro da libertação o que constitui também a tarefa das igrejas no que diz respeito à educação. "A tarefa imprescindível e inadiável das igrejas e da educação teológica é fomentar o amor, o diálogo, o perdão, a reconciliação. Somente neste fundamento pode haver debate sobre a verdade" (SINNER, 2015, p. 4). Da elaboração de Assmann, destaca o aspecto da educação como luta contra a exclusão diante das organizações econômicas e de mercado. A educação, portanto, possui um papel salvífico, além de ser importante fator para o fomento da solidariedade e da cidadania (SINNER, 2015). De Freire, por sua vez, dá especial atenção ao modelo de igreja profética e à sua educação para a libertação. Esta igreja comprometida é aquela, que de forma análoga a Cristo, se coloca a caminho reinventando-se, diante do que rememora a ideia de ecclesia semper reformanda (igreja sempre em reforma). Esta igreja expõe-se "[...] ao risco de fazer parte das lutas

8Informações sobre a consulta geminada ver: R-E-T. The idea. Disponível em <https://r-et.net/en.inhalt/index.html>. Acesso 26 jun. 2018. 
dramáticas da realidade. Não existe profetismo sem risco. Nesta linha, a educação deve ser, de fato, transformadora [...]" (SINNER, 2015, p. 5).

A contribuição de Freire, formulada em 1971, deve ser lida no contexto de efervescência da Teologia da Libertação no contexto latino-americano, do engajamento de teólogos e teólogas profissionais, de religiosos e religiosas, além de leigos e leigas, com as comunidades eclesiais de base (CEBs), com as pastorais, com a luta política e a resistência à ditadura. Desta forma, ao fazer referência a um movimento teológico e à atuação eclesial, deve se ter em mente a seguinte formulação dos irmãos Boff, apesar de posterior ao texto de Freire, em seu clássico Como fazer Teologia da Libertação: "Ora, antes de constituir um novo método teológico, a Teologia da Libertação é um novo modo de ser teólogo" (BOFF, C.; BOFF, L., 2010, p. 38).

Pedagogia e Teologia se relacionam numa gratuidade profética em que o movimento da educação é também teológico, pois encarna-se na realidade concreta da vida das pessoas em busca da salvação social compartilhada. Com efeito, a perspectiva freireana, comum à Teologia da Libertação, de leitura da realidade a partir de baixo, permite que se pense uma pedagogia da gratuidade com o olhar voltado para o humano, sobretudo aqueles e aquelas que mais sofrem.

Com Freire, portanto, atenta-se à dimensão profética de uma pedagogia da gratuidade, o que reforça a perspectiva contextual dessa proposta de cultura humanista. O veio profético da relação com o espaço público é também expressado pelo teólogo sul-africano John de Gruchy (2007, p. 38) em sua proposição de teologia pública enquanto teologia social que, por haurir da tradição profética bíblica, "[...] se coloca ao lado daqueles que não tem poder contra os poderosos [...]"9, relacionandose de forma dialógica com estes não poderosos e articulando sua mensagem como denúncia dos abusos dos detentores do poder.

\footnotetext{
9"[...] sides with the powerless against the powerful [...]".
} 


\section{Categorias de uma pedagogia da gratuidade}

Retomam-se agora os elementos que compõem a teologia da graça, considerando-as em sua força pedagógica e como tripé da pedagogia da gratuidade, a saber, as pedagogias da criatividade, reconciliação e esperança. Cada um dos lados desse triângulo é constituído por uma dessas pedagogias, sendo que ao longo da história, seus lados vão sendo alterados. O baricentro, que é representado pela dimensão ética da graça, o cuidar, está dinamicamente passando por alterações; um lado se expandindo diante dos outros dois e, portanto o baricentro se movimentando.

As características singulares de cada uma das citadas pedagogias, que ancoram a pedagogia da gratuidade, estão categorizadas em: formação, construção, conhecimento, existência, espiritualidade, toque, valor, vontade e fé. Cada uma delas é representada por um triângulo, com o seu baricentro próprio, entendendo que diferentes contextos implicam em lados distintos, ou seja, de acordo com as demandas históricas, cada um dos elementos que formam a categoria, em algum momento, pode ter prevalência em relação aos outros. Esses elementos possuem também compreensões diferentes ao longo do processo histórico, tanto na perspectiva da sincronicidade, como também assincronicidade, de modo que numa avaliação retrospectiva se possa averiguar que determinados contextos talvez carecessem de uma ênfase em dimensões que não receberam a devida prevalência. Entendemos pois, que diferentes conceitos são trabalhados e construídos de forma diferente ao longo do tempo e ao mesmo tempo, tanto em diferentes concepções, como também em distintos autores(as), entendendo sempre que homens e mulheres se fazem ao longo de sua história, produzindo sua existência pelo seu trabalho, conflito, razão, emoção e contradição, sendo pois a humanização um processo, um eterno devir.

Percebemos, intuitivamente, que os diversos elementos das categorias possuem uma dialogicidade permanente, em um ziguezaguear constante de alternâncias baricêntricas. As categorias e os elementos de cada uma são: pedagogia da criatividade: formação (cidadania, ética, educação), construção (engajamento, autonomia, emancipação), conhecimento (conhecer o outro, com o outro, para o outro); pedagogia da reconciliação: existência (dignidade, alteridade, 
relacionalidade), espiritualidade (do toque, da existência, da práxis), toque (abraçar, olhar, escutar); pedagogia da esperança: valor (andrea, aletheia, moira); vontade (expectativa, ser inacabado, ser mais); fé (confiança, convivência, coragem). A seguir, portanto, buscamos desenvolver os elementos e categorias constituintes do tripé pedagógico que sustenta a presente proposta de uma pedagogia da gratuidade.

A pedagogia da criatividade reúne as categorias formação, construção e conhecimento. Pensa-se aqui numa formação continuada, pois se realiza pela via da linguagem e, pois: "Como é possível a formação de um educador sem uma excelente base de linguagem - não digo língua, porque a linguagem é bem mais que isso - e sem uma excelente base do discurso? E sem o conhecimento de história?" (FREIRE, 2001, p. 240). O docente (e não somente ele) carece de formação continuada e, mais que isso, tem direito a ela, pois a vida é um processo de formação permanente. Não se é formado para viver, mas é formando-se que se vive, ou seja, a vida é a própria formação. Nesta dimensão da formação tem-se a educação, a ética e a construção da cidadania. Com Freire (1983, p. 28) percebemos que a "educação tem um caráter permanente. Não há seres educados e não educados. Estamos todos nos educando. Existem graus de educação, mas estes não são absolutos". Esta compreensão nos permite afirmar que o ser humano experiencia um constante aprendizado, inexistindo uma ignorância absoluta, pois existem diferentes saberes, sendo que a sistematização desses saberes pode não existir ou estar em graus diferentes de construção.

A ética, aqui, não é apresentada como um conjunto de regramentos ou de imposição de jeito de ser, mas como "a própria vida, quando conforme os costumes considerados corretos" (VALLS, 2008, p. 7). Esta percepção aponta para a construção de uma cidadania, sendo esta forjada ao longo da vida, esta que se vive existencialmente. Ao tratar sobre educação pensamos que modelo de sujeito humano estamos nos propondo a formar e que horizonte de sociedade temos em vista. As diversas dimensões do corpo, da ética, da afetividade/efetividade, da própria intuição e da espiritualidade estão na mira de mutilações nos modos de se tratar a educação e o processo de produção de conhecimento. Freire (1992, p. 36) nos chama atenção para o entendimento de que conhecer é um ato necessariamente dialógico, pois "o conhecimento se constitui nas relações homem-mundo, relações de transformação, e se aperfeiçoa na problematização crítica dessas relações". 
Ao tratar o conhecimento como dialogicidade o fazemos na própria esfera da ciência, pois esta acontece na produção científica com o outro, ou seja, a ciência não é uma realização solitária, mas solidária. Esta solidariedade não é uma mera participação, é, pois, uma busca de conhecer o outro. Entretanto, não é um buscar para dominar esse outro, mas para poder caminhar juntos. Assim, afirmamos que o desejo precisa estar assentado sobre a comunhão e não sobre a dominação. Esse campo se revela dialógico na medida em que o conhecimento se produz em liberdade para o outro. Pensar nessa esteira é ter em perspectiva que o conhecimento é fruto do encontro permanente com o outro, mediatizado pelo mundo que está em movimento e transformação constantes. Esse processo de produção científica é relacional, sendo sua ocorrência entre seres humanos que se educam ao conhecerem o outro, com o outro e para o outro.

A construção da formação, por sua vez, solicita engajamento, autonomia e emancipação. Com efeito, "o compromisso, próprio da existência humana, só existe no engajamento com a realidade, de cujas 'águas' os homens verdadeiramente comprometidos ficam 'molhados', ensopados. Somente assim o compromisso é verdadeiro." (FREIRE, 1983, p. 19). Assim, engajar-se com a vida em sua concretude não pode ser uma atitude passiva, mas estabelece uma exigência cuja base é um agir e um refletir. Esse engajamento tem relação direta com a construção da autonomia, e esta:

[...] enquanto amadurecimento do ser para si, é processo, é vir a ser. Não ocorre em data marcada. É nesse sentido que uma pedagogia da autonomia tem de estar centrada em experiências estimuladoras da decisão e da responsabilidade, vale dizer; em experiências respeitosas da liberdade (FREIRE, 1996, p. 121).

A autonomia é um processo de amadurecimento, que acontece na vida, tendo como ponto de vista a tomada de decisões e suas consequências, dentro de uma opção de responsabilidades, tanto sob perspectiva individual como também social. $O$ próprio Freire (1996, p. 66) diz que: "o respeito à autonomia e à dignidade de cada um é um imperativo ético e não um favor que podemos ou não conceder uns aos outros". Não sendo um favor, é um critério, que na obra freirena é a definição de ser humano, sendo este um critério histórico-social, referente às possibilidades realmente existentes. Entendemos não ser possível conceber uma ação educativa, que 
visa a emancipação, a transformação, a transgressão, se não há, efetivamente, um topos de dialogicidade. A emancipação é uma via profunda na crença da capacidade humana de encontrar soluções criativas que propiciem a superação da alienação, da opressão e de todas as formas de submissão. Aqui pensamos que a emancipação é uma humanização, em que se planta esperança e se colhe encantamento e isso é tão somente feito pelo diálogo, que é um choque de ideias, em que se requer análise interna, enquanto a exposição de um assunto é algo de origem exógena. A pedagogia do diálogo é uma pedagogia da pergunta, é fenomenológica e provocativa.

Essas ditas três dimensões da pedagogia do diálogo apontam para um educador tratando e vivenciando no gerúndio, ou seja, um educador sendo. A primeira dessas dimensões é a da pergunta, pois quanto mais se pergunta, mais se alarga e aprofunda o diálogo. Esta pedagogia é provocativa, buscando sempre evitar respostas simplistas e reducionistas. Para além disso, a pedagogia do diálogo é fenomenológica, precisando e carecendo ser uma pedagogia sem pressa, em que exista um demorarse, uma degustação, uma penetração, um perscrutar, onde existe um aprender sempre em um processo libertário, que objetiva a emancipação das densas forças sociais de caráter ideológico imiscuídas no senso comum. Emancipar-se, portanto, é um atirar-se para além de si mesmo, no sentido de ser mais.

Na chave de uma hermenêutica da carne (KEARNEY, 2015), ou hermenêutica do toque, pensemos a pedagogia da reconciliação sob seus aspectos relacionais: reconciliação consigo mesmo, com o outro, com os outros (coletividade, comunidade), com o mundo (casa comum). Chamemos este centro relacional da existência humana de espiritualidade.

A espiritualidade não tem a ver com doutrinas, mas com experiências, assim faz-se necessário abordar o tema no "contexto dramático, perigoso e esperançador em que se encontra atualmente a humanidade" (BOFF, 2001, p.10). A espiritualidade é a transformação que a mística produz nos diferentes sujeitos no que se refere à forma de olhar a vida, no jeito de encarar os problemas e de encontrar os caminhos, possibilitando alternativas e soluções.

A espiritualidade de uma pessoa se revela diante da alteridade, do reconhecimento da própria vida como mistério que escapa às teorizações. $A$ 
espiritualidade pertence à vida, é uma constante antropológica, movimento de compreensão e incompletude.

Importante retomar a expressão mística. No campo do senso comum é uma reflexão que esgotou as capacidades da razão e não consegue mais produzir luz. $A$ palavra mística tem origem no grego muein, que é traduzida também por mistério (cf. LEXICO, 2020). Percebe-se aí o caráter da abscondicidade, não comunicado de uma realidade ou de uma intenção. O mistério não equivale a um enigma, que ao ser decifrado desaparece, pertencendo ao mistério ser conhecido e ao mesmo tempo continuar mistério no conhecimento. Caminhamos, assim, pela compreensão do estabelecimento de uma categorização que trafega pela espiritualidade do toque, da existência e da práxis.

Comecemos pela espiritualidade da existência. Existir "ultrapassa viver porque é mais do que estar no mundo; é estar nele e com ele”. (FREIRE, 2000, p. 48). Entender existir nessa linha nos leva imediatamente a pensar que este “... é um conceito dinâmico. Implica numa dialogação eterna do homem com o homem. Do homem com o mundo. Do homem com o seu criador" (FREIRE, 2000, p. 68). A intuição nos possibilita abordar que na espiritualidade da existência está o relacionamento e neste está gestada a fraternidade e a sororidade (somos todos e todas irmãos e irmãs, como propõe a recente encíclica Fratelli Tutti, de Francisco); com o mundo estabelecese a conexão de fruição; com o mistério aspira-se a plenitude e as respostas existenciais. Essas demandas se dão na experiência do êxtase, na experiência do respeito, no experienciar da vida, desde a criança que nasce àquela que falece, desde um rosto sofrido ao pés e mãos calejadas, desde a falta do abraçar, do escutar e do olhar, à presença que marca ao deixar-se viver exponencialmente o caminhar e compartilhar.

Ao tratarmos sobre esses três verbos (abraçar, escutar e olhar) estamos no campo da espiritualidade do toque, esta que envolve a corporeidade em sua totalidade. Esta espiritualidade tem a ver com a pele, com os poros; tem ligação com o coração (cuja centralidade é a da razão e da emoção) sem dicotomia. Coração por onde passa o sangue que transmite/liga, por ser bombeado por todo lado. A espiritualidade do toque é algo raso (epitelial) pois está na dimensão do campo dos poros, muitas vezes aponta para situações aporéticas (sem saída); 
simultaneamente é profunda, pois esse órgão (a pele) tem conexões basilares com o interno, desde o coração ao pulmão; ela (a pele) tem contato com o externo, mas não somente ela, destacaremos aqui o escutar e o olhar. Ambos na dimensão do sentir. $O$ primeiro se vincula à audição; já o segundo à visão. $O$ raso e 0 profundo se presentificam em ambos os sentidos. A espiritualidade do toque nos remete a uma experiência com o próprio mistério da existência, que ocorre ao tocar (seja abraçar, escutar ou olhar). Esses três verbos, esses três lados de um triângulo, estão em constante movimentação em sua dimensão, alterando constantemente seu baricentro.

Ainda no campo da espiritualidade, temos a da práxis, sendo ela "a capacidade de atuar, operar, de transformar a realidade de acordo com finalidades propostas pelo homem, à qual está associada sua capacidade de refletir, que o faz um ser da prática." (1983, p.17). Ou ainda quando o mesmo Freire (1992, p.80) diz: "Práxis na qual ação e reflexão, solidárias, se iluminam constantemente e mutuamente. Na qual a prática, implicando na teoria da qual não se separa, implica numa postura de quem busca 0 saber, e não de quem passivamente o recebe". A práxis é um termo grego que é traduzido por ação, mas num sentido de inseparabilidade entre o agir e o pensar, pois estas duas dimensões não acontecem de forma separada, ou seja, o refletir e o agir são uma ação conjunta. Esta espiritualidade é integral, visceral em sua organicidade e existência, algo que passa pelo corpo em sua integralidade e contradição. A ideia da práxis, como esse movimento visceral de teoria e prática, aponta para uma vital reflexão sobre espiritualidade.

Só há salvação para quem não é perfeito, para quem espera algo. Nesse sentido, uma pedagogia da esperança imbrica vontade, valor e fé. A fé aqui disposta é a tradução imediata da esperança, confiança em algo que se espera, mesmo que contra toda esperança. É convicção de superação do desespero, da angústia, das aporias. A confiança, como propõe Rudolf von Sinner (2007), é a base da convivência. Con-viver e co-existir, por sua vez, invocam a alteridade sem a qual não sou.

O ser mais é um valor e está na categoria da vontade e, como tal se comunica com o existir e com o poder. No campo do valor seus laços são com a coragem (andrea), verdade (aletheia) e destino (moira). Essas são três divindades femininas das narrativas míticas gregas. Andrea é tal qual a compreensão em que "a educação é um ato de amor, por isso, um ato de coragem. Não pode temer o debate. A 
análise da realidade não é fugir à discussão criadora, sob pena de ser uma farsa" (FREIRE, 2000, p. 104). A coragem é uma dignidade, constituída ao lado de aletheia (verdade). Esta, não tendo como ponto de partida a verdade enquanto correspondência, mas sim como ousadia (parrhesia). A verdade vincula-se ao destino, ou seja, Aletheia anda de mãos dadas com Moira. Essas divindades se presentificam na formação e acontecem, quer se queira ou não, desde que a vida começa e, não se educa simplesmente para, vai-se além, pois em si sendo, a educação já é. Esse já é, é da instância de um ser sendo, de um ser-aí (cf. HEIDEGGER, 2007), que se coloca na imediaticidade do ser, desde um lá a um cá. Destino (moira) como o futuro do que o ser humano fará dele agora, ou razoavelmente como aponta Freire (2003, p. 149): "na concepção dialética, por isso mesmo não mecanicista, da história, o futuro eclode da transformação do presente como um dado dando-se. Daí o caráter problemático e não inexorável do futuro" A história é construída por homens e mulheres a partir de seu engajamento, produzido na construção da autonomia visando a emancipação, que carrega a intencionalidade de um intervir ativamente, traduzindo uma consciência de que o futuro, tido como destino é (re)feito na luta de todos os dias.

A vontade como uma dessas nossas categorias, se expressa por meio da esperança, o ser inacabado e o ser mais. Freire (1996, p. 80-81) afirma que a esperança

[...] faz parte da natureza humana. Seria uma contradição se, inacabado e consciente do inacabamento, primeiro, o ser humano não se inscrevesse ou não se achasse predisposto a participar de um movimento constante de busca e, segundo, se buscasse sem esperança. A esperança é uma espécie de ímpeto natural possível e necessário, a esperança é um condimento indispensável à experiência histórica. Sem ela, não haveria história, mas puro determinismo. Só há história onde há tempo problematizado e não prédatado. A inexorabilidade do futuro é a negação da história.

A esperança não somente está, mas é pertencente às experiências do ser humano. De maneira isolada ela é sonolenta, entorpecida, imóvel. Ela, em seu imperativo existencial é uma força propulsora para o realizar. A esperança possui sua dimensão ôntica (ímpeto), sendo traduzida ontologicamente numa práxis pela via da concretude histórica, condição essa, que não pode ser abandonada em vista da conscientização de uma luta (polemos) em torno de um ser inacabado. 
Freire (1996, p. 55) diz que o "inacabamento do ser ou a sua inconclusão; é próprio da experiência vital. Onde há vida, há inacabamento". Animais e plantas são inacabados, entretanto, somente o ser humano possui a consciência desse inacabamento. Ao pensar nesse caminhar, entendendo aqui este como a abertura de um caminho, configura-se em forma de correspondência, um método, ou seja, um jeito de realizar; ao fazer isto estamos tomados diretamente pela esperança, pois esta é uma realização. Sobre o inacabamento, nos diz Freire (1983, p. 27-28) sem pestanejar que "[...] a educação é possível para o homem, porque este é inacabado e sabe-se inacabado. Isto o leva à sua perfeição". É na condição de inacabamento que a formação, enquanto dimensão da educação é essencial, acolhe-se a insuficiência como algo que é próprio do humano e o abre à alteridade.

Desse ser inacabado somos levados ao ser mais. "Um" e "outro" não são "um" e "outro", tal como uma relação entre dois, onde cada qual está em um lugar e tempos distintos. "Um" e "outro" são UM/OUTRO. É um só ser: um ser inacabado e ser mais. Esta última dimensão, a do ser mais, é uma práxis da valorização do indivíduo como ser humano. Essa dimensão é a busca pela liberdade, que é uma conquista, jamais uma concessão. Ao ser assim, o ser mais é a consciência do inacabamento, ao qual Freire (2003, p. 192) assim diz: "Não hesitaria em afirmar que, tendo-se tornado historicamente o ser mais a vocação ontológica de mulheres e homens, será a democrática a forma de luta ou de busca mais adequada à realização humana do ser mais".

Nesta dita vocação ontológica, o ser humano é um ser mais, é um ser inacabado e, como tal carece de dialogicidade, este que concebe o diálogo como única possibilidade para a produção epistêmica: de si mesmo, do outro e, de tudo que o cerca, em uma procura sem fim do objeto cognoscente, sempre em uma companhia permanente, de uma dita presença, seja ela presente ou ausente. Este aparente paradoxo, está envolvido no diálogo, pois o ser dialógico intenciona o ser mais, partilhando com o outro não só o privilégio do conhecer, mas, ao mesmo tempo, o desejo do saber. O ser mais é um ser dialógico, sendo um "empenhar-se na transformação constante da realidade" (FREIRE, 1992, p. 43). 


\section{Considerações Finais}

O presente trabalho assumiu o desafio de abrir caminhos do pensar, pelas veredas dos pensamentos barthiano e freireano. $\mathrm{Na}$ tentativa de análise e síntese, elaborou-se a presente proposta de uma pedagogia da gratuidade com enfoque na criatividade, reconciliação e esperança. Reconhece-se o estágio ainda embrionário desta abordagem, entretanto, também se considera sua potencialidade para ulteriores desenvolvimentos em pesquisas futuras.

A pedagogia da gratuidade diz respeito à graça da vida e suas relações. Ser com o outro, co-humanidade no vocabulário barthiano, indica a possibilidade de ser mais, ser não apesar das contingências, mas com elas. Ser humano, humanizar-se é ser com o outro, para o bem do outro, em diaconia (serviço) quenótica (esvaziamento de si em favor do outro), comunional (koinonia) e em abertura. Como se percebe, ainda outros termos e sentidos se podem agregar às categorias de uma pedagogia da gratuidade que se movimenta pericoreticamente, entre criatividade, reconciliação e esperança, na interpenetração de categorias e elementos sempre abertos a ser mais, numa força ética de humanização como telos (finalidade) pedagógico e teológico.

Seguir todo esse trilho é pensar a conexão entre ética barthiana em relação crítica e dialógica com as publicações de Paulo Freire, intuindo desdobramentos triangulares do tripé criatividade-reconciliação-esperança. Em resumo, as imbricações existenciais entre a teologia barthiana e a pedagogia freireana desenvolvem elementos referenciais para uma cultura de humanização, como horizonte da assim chamada pedagogia da gratuidade. O cuidar, compreendido aqui como dimensão ética da gratuidade, é o baricentro de todos os triângulos, de tal modo que, independentemente das condições históricas e do ziguezaguear das estruturas triangulares, há uma disposição central de ser com o outro e, no reconhecimento e acolhida do próprio inacabamento, ser mais. Sou mais doando-me!

\section{Referências}

BARTH, K. (1978). The Church Dogmatics: The Doctrine of Creation. v. III.4. Edinburgh: T\&T Clark. 
BARTH, K. (1983). Church Dogmatics: The Doctrine of God. v. II.2. Edinburgh: T\&T Clark.

BARTH, K. (2016). A Carta aos Romanos: (segunda versão) 1922. São Leopoldo: Sinodal/EST.

BOFF, C. (2014). O livro do sentido: crise e busca de sentido hoje (parte críticoanalítica). v.1. São Paulo: Paulus.

BOFF, C.; BOFF, L. (2010). Como fazer teologia da libertação. Petrópolis: Vozes.

BOFF, L. (2000). A Santíssima Trindade é a melhor comunidade. Petrópolis: Vozes.

FRANCISCO. (2020, octubre, 03). Carta Encíclica Fratelli Tutti. Sobre a fraternidade e a amizade social. Recuperado de

http://www.vatican.va/content/francesco/pt/encyclicals/documents/papa-

francesco 20201003 enciclica-fratelli-tutti.html.

FREIRE, P. (2011). Ação cultural para a liberdade e outros escritos. Rio de Janeiro:

Paz e Terra. (Versión ePub).

FREIRE, P. (2003). Cartas a Cristina: reflexões sobre minha vida e minha práxis.

São Paulo: Unesp.

FREIRE, P. (2000). Educação como prática de liberdade. Rio de Janeiro: Paz e Terra.

FREIRE, P. (1983). Educação e mudança. Rio de Janeiro: Paz e Terra.

FREIRE, P. (1992). Extensão ou comunicação? Rio de Janeiro: Paz e Terra.

FREIRE, P. (1996). Pedagogia da autonomia: saberes necessários à prática educativa. Rio de Janeiro: Paz e Terra, 1996.

FREIRE, P. (2007). Pedagogia da esperança: um reencontro com a pedagogia do oprimido. Rio de Janeiro: Paz e Terra, 2007.

FREIRE, P. (2014). Pedagogia da tolerância. São Paulo: Editora Paz e Terra, 2014.

FREIRE, P. (1997). Pedagogia do oprimido. Rio de Janeiro: Paz e Terra.

FREIRE. P. (2001). Pedagogia dos sonhos possíveis. Organização, apresentação e notas de Ana Maria Araújo Freire. São Paulo: Editora Unesp.

GRUCHY, J. (2007). Public Theology as Christian Witness: exploring the genre. International Journal of Public Theology, v. 1, pp. 26-41, doi:

https://doi.org/10.1163/156973207X194466. 
HEIDEGGER, M. (2007). Ser e Tempo. Tradução de Márcia de Sá Cavalcanti. Petrópolis: Vozes.

JEANROND, W. (2010). A theology of love. London: T\&T Clark.

KEARNEY, R. (2015). The wager of carnal hermeneutics. in KEARNEY, R.; TREANOR, B. (Eds.). Carnal hermeneutics (pp. 15-56). New York: Fordham University Press.

KEARNEY, R. (2014, Agosto, 30). Losing our touch. The New York Times.

Opinionator. Recuperado de

https://opinionator.blogs.nytimes.com/2014/08/30/losing-our-touch/.

LEXICO. (2020) Mystic. Oxford Dictionaries. Recuperado de:

https://www.lexico.com/definition/mystic.

MOLTMANN, J. (2005). Teologia da esperança: estudos sobre os fundamentos e as consequências de uma escatologia cristã. São Paulo: Teológica/Loyola.

RICOEUR, P. (2002). "O bom uso das feridas da memória”. Textos Traduzidos de Paul Ricoeur. Instituto de Estudos Filosóficos. Universidade de Coimbra.

Recuperado de

https://www.uc.pt/fluc/uidief/textos ricoeur/o bom uso das feridas da memoria.

SINNER, R. (2007). Confiança e convivência: reflexões éticas e ecumênicas. São Leopoldo: Sinodal.

SINNER, R. (2015). As igrejas no espaço público: rumo a uma teologia pública com enfoque na cidadania. Recuperado de https://r-

e299t.net/fix/files/von\%20Sinner teologia\%20p\%FAblica cidadania \%20in\%20Portu gues.pdf.

SOBRINO, J. (1990). Centralidad del reino de Dios en la teología de la liberación. in ELLACURÍA, Ignacio; SOBRINO, Jon. (Orgs.). Mysterium Liberationis: Conceptos fundamentales de la teología de la liberación (pp. 467-510). v.1. Madrid: Editorial Trotta.

TRACY, D. (2006). A imaginação analógica: a teologia cristã e a cultura do pluralismo. São Leopoldo: Editora UNISINOS.

VALLS, Álvaro L.M. O que é ética. São Paulo: Editora brasiliense. 2008. (Coleção Primeiros Passos)

WESTHELLE, V. (2012). Eschatology and space: the lost dimension in theology past and present. New York: Palgrave Macmillan. 
ZEFERINO, J. (2019). A política como assunto dos estudos em teologia pública: aportes na relação entre religião e espaço público à luz da tipologia de teologia públicas de Boaventura de Sousa Santos. Caderno Teológico, v. 4, n. 2, pp. 67-79, doi: http://dx.doi.org/10.7213/2318-8065.04.02.p67-79.

ZEFERINO, J. (2020). A teologia pública no Brasil: análise de um mapeamento. Interações, v. 15, n. 1, pp. 90-107, doi: https://doi.org/10.5752/P.19832478.2020v15n1p90-107.

ZEFERINO, J. (2018). Karl Barth e teologia pública: contribuições ao discurso teológico público na relação entre clássicos teológicos e res publica no horizonte da teologia da cidadania. Tesis doctoral en Teología. Pontifícia Universidade Católica do Paraná, Brasil.

ZEFERINO, J.; FERNANDES, M. L. (2020). O sofrimento dá o que pensar: teologia pública em diálogo com a literatura marginal. Teoliterária, v. 10, n. 21, pp. 470-497, doi: https://doi.org/10.23925/2236-9937.2020v21p470-497.

Manuscrito recebido em: 17 de novembro de 2020

Aprovado em: 23 de dezembro de 2020

Publicado em: 31 de dezembro de 2020 